\title{
COLOR STABILITY OF ARTIFICIAL WHITE SPOT LESIONS TREATED WITH RESIN INFILTRATION
}

\author{
Marwa I. AbdelHafez *, Dena S. Mustafa ${ }^{* *}$ and Khaled A. Nour ${ }^{* * *}$
}

\begin{abstract}
Objective: To evaluate the color stability of artificial white spot lesions treated with three different surface treatments after immersion in staining solution.

Materials and Methods: An artificial white spot lesion was created in the middle of the labial surface using demineralizing solution. Sixty-five bovine teeth were randomly assigned into 5 groups ( $n=13$ ) according to surface treatment. G1: Enamel submitted to demineralization only. G2: Polished Enamel. G3: Demineralized enamel treated with low-viscosity resin infiltrant. G4: Demineralized enamel treated with CPP-ACP for 1 month. G5: Demineralized enamel treated with Artificial saliva for 1 month. All specimens were then immersed in a staining solution (coffee) for 8 weeks. Color measurements, using the CIE L*a*b* system, were done immediately after treatment and after 2, 4 and 8 weeks of immersion, by Spectrophotometry. Digital photographs were also taken at each stage to a representative specimen from each group. In addition, representative specimen for each group was evaluated using Polarized Light microscope. Color change $(\Delta \mathrm{E})$ was analyzed by two-way mixed ANOVA.
\end{abstract}

Results: Resin infiltrant group exhibited the lowest color change values at all times of measurement, followed by CPP-ACP and polished enamel, while the highest color change values were recorded in samples without treatment.

Conclusion: Resin infiltrant can be considered an effective treatment in masking and reducing long-term staining susceptibility of white spot lesions after treatment.

KEYWORDS: Color stability, Artificial white spot lesion, Resin infiltrant, Amorphous calcium phosphate, Spectrophotometer.

\footnotetext{
* Master's student, Operative Dentistry Department, Faculty of Dentistry, Ain Shams University, Cairo, Egypt. ** Lecturer, Operative Dentistry Department, Faculty of Dentistry, Ain Shams University, Cairo, Egypt.

*** Associate Professor, Operative Dentistry Department, Faculty of Dentistry, Ain Shams University, Cairo, Egypt.
} 


\section{INTRODUCTION}

White spot lesions are considered the earliest evidence of dental caries, which can be caused by imbalance between demineralization and remineralization processes. ${ }^{1}$ White spot lesions can present on any tooth surface where the microbial biofilm is allowed to develop and remain for a prolonged period of time. ${ }^{2}$

The subsurface porosity of WSLs caused by enamel demineralization develops a different refractive index (1.00) than hydroxyapatite (1.62$1.65)$, and is noticeable when dehydration of the lesion is performed. This heterogeneity leads to light scattering and the appearance of dull whitish discoloration. ${ }^{3}$ Increased opacity is correlated to extensive and increased porosity. ${ }^{4}$ When these porosities are filled with an aqueous solution having similar refractive index to hydroxyapatite, the opacity seemingly disappears and enamel regains its translucency. ${ }^{3}$

Several treatments have been proposed for arresting the lesion and masking this whitish discoloration, starting from management of the dietary habits and utilizing a therapeutic spectrum that saves the pseudo-intact surface layer maintaining tooth integrity and blocking the porosities against further diffusion of acids and chromophores. ${ }^{5}$

Non-invasive treatments aim at arresting or reversing the white spot lesions. It involves topical application of remineralizing agents on the enamel surface. ${ }^{6}$ They may be in the form of pastes, cream like casein-phosphopeptide - Amorphous calcium phosphate (CCP-ACP), or varnishes like fluoride. ${ }^{7}$ These treatments can effectively promote remineralization of the sub-surface lesions. ${ }^{8,9}$ However, these agents are subject to dilution and washing out by saliva. ${ }^{10}$ They also require time and patient compliance. $^{3}$

Further along the therapeutic spectrum, microinvasive techniques involve filling the pores within the body of the lesion with a low-viscosity lightcured resin, therefore, preventing further dissolution of enamel by acidic challenges. ${ }^{6}$. The concept of resin infiltration has been proposed in order to combine both non-invasive and immediate esthetic outcomes in more challenging WSLs. ${ }^{11}$ Owing to its low viscosity, resin infiltrant $\left(\mathrm{ICON}^{\circledR}\right)$ can fill the pores and thus prevents further diffusion of bacteria, and consequently, impedes lesion development. ${ }^{3}$

In addition, resin infiltration has the ability to mask the whitish, opaque color of the lesion by altering its refractive index to approach that of the remaining tooth structure and therefore enhancing the final tooth appearance. ${ }^{3,12}$

Since white spot lesions are often present in the esthetic zone, huge efforts have been made to mask their opaque color. In addition, color stability of different treatment modalities are very important in evaluating their long-term success. ${ }^{13}$. Even more, further testing of these materials for their staining susceptibility when exposed to different colorants is still needed.

From this aspect, this study aims to evaluate the color stability of artificial white spot lesions treated with resin infiltrant, or remineralization, by either CPP-ACP or artificial saliva after immersion in a staining solution.

\section{MATERIALS AND METHODS}

\section{Specimen preparation}

Bovine teeth were cleaned from blood and soft tissue. Each specimen was placed in a cylindrical PVC ring, with the labial surface directed downwards on a glass slab to embed in self-polymerizing acrylic resin (Acrostone, Egypt). ${ }^{13,14}$ For standardized and repeated positioning of specimens at the different times of measurements, a groove was made on the side of each resin block using fissure bur (MANI ${ }^{\circledR}$, Japan). ${ }^{14}$ Enamel surfaces were then polished with silicon carbide polishing papers $(180,600,1200$ grits) in ascending fineness followed by ultrasonic 
cleaning for 15 minutes to ensure removal of all surface debris. . $^{15,16}$

\section{Grouping of specimens}

Sixty-five bovine teeth were randomly assigned into five groups $(n=13)$ according to surface treatment.G1: Enamel submitted to demineralization only; without treatment. G2: Polished Enamel. G3: Demineralized enamel treated with resin infiltrant. (ICON®, DMG, Hamburg, Germany). G4: Demineralized enamel treated with CPP-ACP for 1 month. (GC Tooth Mousse ${ }^{\circledR}$, GC Tokyo, Japan). G5: Demineralized enamel treated with Artificial saliva for 1 month. Sample size calculation was performed using $\mathrm{G}^{*}$ Power (Version 3.1.9.2 2) to set power $=95 \%{ }^{1}$

\section{Preparation of artificial white spot lesions:}

The working area of each specimen was demarcated using a $6 \mathrm{~mm} \times 6 \mathrm{~mm}$ graph paper in the middle of the labial surface representing the area exposed to demineralizing solution. The rest of the enamel surface was protected by two coats of acidresistant nail varnish (Revlon Consumer Products Corporation, New York, USA). ${ }^{17,18}$ Specimens were immersed in a demineralizing solution containing $2.2 \mathrm{mM} \mathrm{CaCl} 2,2.2 \mathrm{mM} \mathrm{KH} 2 \mathrm{PO} 4$, and $50 \mathrm{mM}$ Acetic Acid at $37^{\circ} \mathrm{C}$ for 4 days. ${ }^{19}$ Two milliliters of demineralizing solution was used per each $\mathrm{mm}^{2}$ of the exposed enamel area of each specimen. ${ }^{14}$

\section{Surface treatment of artificial white spot lesions:}

Specimens were exposed to three different surface treatments (resin infiltrant, CPP-ACP and artificial saliva). For the Resin infiltrantion group, resin infiltrant $\left(\mathrm{ICON}^{\circledR}\right)$ was applied according to the manufacturer's instructions.$^{20}$ Hydrochloric acid etchant was applied followed by Icon-Dry and IconInfiltrant. Any excess beyond the lesion peripheries was removed before curing. A layer of glycerin was then applied and light-cured..$^{21}$ The infiltrated surfaces were polished according to manufacturer instructions to remove any surface irregularities.
For the $\boldsymbol{C P P}-\boldsymbol{A C P}$ group, WSLs were treated with GC Tooth Mousse ${ }^{\circledR}$ for 30 minutes and the excess was removed with gauze. Specimens were then rinsed and stored in artificial saliva until the next day. ${ }^{53}$ This remineralization procedure was repeated for 30 days at the same hour and the artificial saliva was changed every day. ${ }^{23}$

For the Artificial saliva group, specimens were stored in artificial saliva of $\mathrm{pH} 7.0$ containing $0.65 \mathrm{~g} / \mathrm{l}$ potassium chloride, $0.058 \mathrm{~g} / \mathrm{l}$ magnesium chloride, $0.165 \mathrm{~g} / 1$ calcium chloride, $0.804 \mathrm{~g} / \mathrm{l}$ dipotassium hydrogen phosphate, $0.365 \mathrm{~g} / 1$ potassium dihydrogen phosphate, $2 \mathrm{~g} / \mathrm{l}$ sodium carboxymethyl cellulose and distilled water. The solution was renewed daily for 30 days. ${ }^{24}$

\section{Staining procedure}

Coffee was selected as the staining solution in this study. A sachet of $1.8 \mathrm{~g}$ of coffee powder (Nescafe ${ }^{\circledR}$ Classic, Nestlè, Switzerland) was poured into $200 \mathrm{~mL}$ of hot water and stirred. The solution was left to cool at room temperature. Each specimen was immersed individually in a separate jar containing coffee and stored at room temperature. Over the span of 8 weeks of immersion, staining solution was changed every 7 days to prevent the growth of bacteria and fungi. ${ }^{14,25}$

Prior to color measurement, specimens were re-polished, rinsed and blot-dried using absorbent papers, then color measurements were obtained. ${ }^{51}$

\section{Colorimetric analysis:}

Digital photographs of representative specimens were obtained under standardized photography settings using DSLR camera. Images were taken immediately after treatment of WSLs and after 2, 4 and 8 weeks of immersion in coffee.

In addition, color measurements were obtained for all the groups according to the Commission International de l'Eclariage (CIE) $\mathrm{L}^{*} \mathrm{a}^{*} \mathrm{~b}^{*}$ values, using Cary 5000 Spectrophotometer (Agilent Technologies, NY, USA). Color measurements 
were obtained immediately after treatment and after 2, 4 and 8 weeks of immersion.

Results of color measurements were quantified in terms of three coordinate values $\left(\mathrm{L}^{*} \mathrm{a}^{*} \mathrm{~b} *\right), \mathrm{L}^{*}$ represents the degree of Lightness (0 black, 100 white), a* represents the degree of green/red color, $b^{*}$ represents the degree of blue/yellow color. The quantitative evaluation of color change $(\Delta \mathrm{E})$ of the test specimens were obtained by the following formula: ${ }^{14}$

$$
\Delta \mathbf{E}=\left(\Delta \mathbf{L}^{2}+\Delta \mathbf{a}^{2}+\Delta \mathbf{b}^{2}\right)^{1 / 2}
$$

A $\Delta \mathrm{E}$ difference of $>3.7$ units is considered a clinical indicator for color change. Hence, $\Delta \mathrm{E} \leq 3.7$ is considered acceptable for color change. ${ }^{43,46,57}$

\section{Polarized Light Microscopy}

A representative sample for each group was prepared to be studied under Polarized Light microscopy before the process of staining. Samples were sectioned longitudinally and mounted on a glass cover slide. ${ }^{8}$ The intended area of WSL was centered in the field of view and photographed at $\times 10$ magnification using Polarized light microscopy (BX60, Olympus, Japan).

\section{Statistical analysis}

Two-way mixed model ANOVA was used to study the effect of different tested variables and their interaction on color stability of artificial WSLs. The significance level was set at $\boldsymbol{p} \leq 0.05$ within all tests.
Mean and standard deviation for each group was calculated. Statistical analysis was performed with IBM ${ }^{\circledR}$ SPSS ${ }^{\circledR}$ Statistics Version 26 for Windows (IBM Corporation, NY, USA).

\section{RESULTS}

Two-way mixed ANOVA test results revealed a significant effect of surface treatment, time of immersion, and their interaction on color change of artificial WSLs $(\boldsymbol{p}<0.001)$ as shown in Table 1.

One-way ANOVA revealed a statistically significant effect of surface treatment on color change of artificial WSLs $(\boldsymbol{p}<0.001)$. The highest value of color change was found in samples without treatment, followed by artificial saliva. Meanwhile, the lowest color change value was recorded by resin infiltration group as shown in Table 2. Pairwise comparisons using Tukey's post hoc test revealed no significant difference between samples treated with CPP-ACP and polished enamel $(\boldsymbol{p}=0.253)$.

One-way repeated measures ANOVA recorded a significant effect of time of immersion on color change of artificial WSLs $(\boldsymbol{p}<0.001)$ as shown in Table 2. Pairwise comparisons utilizing multiple paired $t$-tests with Bonferroni correction showed a statistical significant increase of color change values starting at 2 weeks, followed by 4 weeks; reaching the highest color change value at 8 weeks after immersion in staining solution $(\boldsymbol{p}<0.001)$.

TABLE (1): Two-way mixed ANOVA for the effect of surface treatment, time of immersion and their interactions on color change of artificial white spot lesions.

\begin{tabular}{|c|c|c|c|c|c|}
\hline Source & Sum of Squares & df & Mean Square & F & $\boldsymbol{p}$-value \\
\hline Intercept & 8388.57 & 1 & 8388.58 & 53190.87 & $<\mathbf{0 . 0 0 1 *}$ \\
\hline Surface treatment & 1290.14 & 4 & 322.53 & 2045.16 & $<\mathbf{0 . 0 0 1 *}$ \\
\hline Time of immersion & 202.82 & 2 & 101.41 & 989.27 & $<\mathbf{0 . 0 0 1 *}$ \\
\hline Surface treatment * Time & 18.69 & 8 & 2.33 & 22.79 & $<\mathbf{0 . 0 0 1 *}$ \\
\hline Error (Surface treatment) & 9.462 & 60 & 0.158 & & \\
\hline Error (Time of immersion) & 12.301 & 120 & 0.103 & & \\
\hline
\end{tabular}

$d f=$ degree of freedom*; significant $(p \leq 0.05) n s ;$ non-significant $(p>0.05)$ 
As shown in Table 3, after 8 weeks of immersion in coffee solution, the highest $\Delta \mathrm{L}$ value was recorded by the resin infiltration group, while the lowest $\Delta \mathrm{L}$ value was found in samples without treatment. Meanwhile, $\Delta \mathrm{a}$ value was the highest in samples without treatment, while the lowest $\Delta$ a value was found in CPP-ACP group. Nevertheless, $\Delta \mathrm{b}$ values were the highest in the artificial saliva group, while the lowest $\Delta b$ value was found in polished enamel samples.

TABLE (2): Mean \pm standard deviation (SD) for the effect of different times of immersion at different surface treatments on mean color change $(\Delta \mathrm{E})$ of artificial white spot lesions.

\begin{tabular}{|c|c|c|c|c|}
\hline \multirow{2}{*}{ Surface treatment } & \multicolumn{3}{|c|}{ Time of immersion $($ Mean \pm SD) } & \multirow{2}{*}{$p$-value } \\
\hline & 2 weeks & 4 weeks & 8 weeks & \\
\hline No treatment & $8.38 \pm 0.46^{\mathrm{Ca}}$ & $10.78 \pm 0.48^{\mathrm{Ba}}$ & $11.89 \pm 0.53$ Аа & $<0.001 *$ \\
\hline Polished enamel & $3.85 \pm 0.46^{\mathrm{Cc}}$ & $5.05 \pm 0.33^{\mathrm{Bc}}$ & $6.21 \pm 0.23^{\mathrm{Ac}}$ & $<0.001 *$ \\
\hline Resin infiltration & $2.59 \pm 0.26^{\mathrm{Cd}}$ & $3.54 \pm 0.19^{\mathrm{Bd}}$ & $4.16 \pm 0.18^{\mathrm{Ad}}$ & $<0.001 *$ \\
\hline CPP-ACP & $4.19 \pm 0.37^{\mathrm{Cc}}$ & $5.37 \pm 0.22^{\mathrm{Bc}}$ & $6.11 \pm 0.19^{\mathrm{Ac}}$ & $<0.001 *$ \\
\hline Artificial saliva & $7.07 \pm 0.47^{\mathrm{Cb}}$ & $9.13 \pm 0.28^{\mathrm{Bb}}$ & $10.06 \pm 0.25^{\mathrm{Ab}}$ & $<0.001 *$ \\
\hline$p$-value & $<0.001 *$ & $<0.001 *$ & $<0.001 *$ & \\
\hline
\end{tabular}

Different upper superscript letters indicate a statistically significant difference within the same horizontal row. Different lower superscript letters indicate a statistically significant difference within the same vertical column. *; significant (p $\leq 0.05)$ ns; non-significant ( $p>0.05)$

TABLE (3): Mean \pm standard deviation (SD) of color parameters of different surface treatments after 8 weeks of immersion in staining solution.

\begin{tabular}{|c|c|c|c|}
\hline Color parameter & Surface treatment & Mean \pm SD & $p$-value \\
\hline \multirow{5}{*}{$\begin{array}{c}\Delta \mathbf{L} \\
\text { Light/dark } \\
(+) \text { lighter } \\
\text { (-) darker }\end{array}$} & No treatment & $-9.91 \pm 0.58^{\mathrm{D}}$ & \multirow[t]{5}{*}{$<0.001 *$} \\
\hline & Polished enamel & $-5.13 \pm 0.24^{\mathrm{B}}$ & \\
\hline & Resin infiltration & $-1.45- \pm 0.17^{\mathrm{A}}$ & \\
\hline & CPP-ACP & $-4.97 \pm 0.22^{\text {в }}$ & \\
\hline & Artificial saliva & $-7.90 \pm 0.31^{\mathrm{C}}$ & \\
\hline \multirow{5}{*}{$\begin{array}{c}\Delta \mathbf{a} \\
\text { Red-green } \\
(+) \text { redder } \\
\text { (-) greener }\end{array}$} & No treatment & $5.72 \pm 0.30^{\mathrm{A}}$ & \multirow[t]{5}{*}{$<0.001 *$} \\
\hline & Polished enamel & $3.08 \pm 0.15^{\mathrm{C}}$ & \\
\hline & Resin infiltration & $1.72 \pm 0.19^{\mathrm{D}}$ & \\
\hline & CPP-ACP & $1.41 \pm 0.11^{\mathrm{E}}$ & \\
\hline & Artificial saliva & $4.34 \pm 0.26^{\text {в }}$ & \\
\hline \multirow{5}{*}{$\begin{array}{c}\Delta \mathbf{b} \\
\text { Yellow-blue } \\
(+) \text { yellower } \\
(-) \text { bluer }\end{array}$} & No treatment & $3.12 \pm 0.26^{\mathrm{C}}$ & \multirow[t]{5}{*}{$<0.001 *$} \\
\hline & Polished enamel & $1.67 \pm 0.11^{\mathrm{D}}$ & \\
\hline & Resin infiltration & $3.48 \pm 0.22^{\mathrm{B}}$ & \\
\hline & CPP-ACP & $3.25 \pm 0.14^{\mathrm{BC}}$ & \\
\hline & Artificial saliva & $4.46 \pm 0.35^{\mathrm{A}}$ & \\
\hline
\end{tabular}

Different superscript letter indicates a statistically significant difference within the same vertical column and color parameter *; significant ( $p \leq 0.05)$ ns; non-significant $(p>0.05)$ 
POLARIZED LIGHT MICROSCOPIC EVALUATION OF ENAMEL SURFACE:

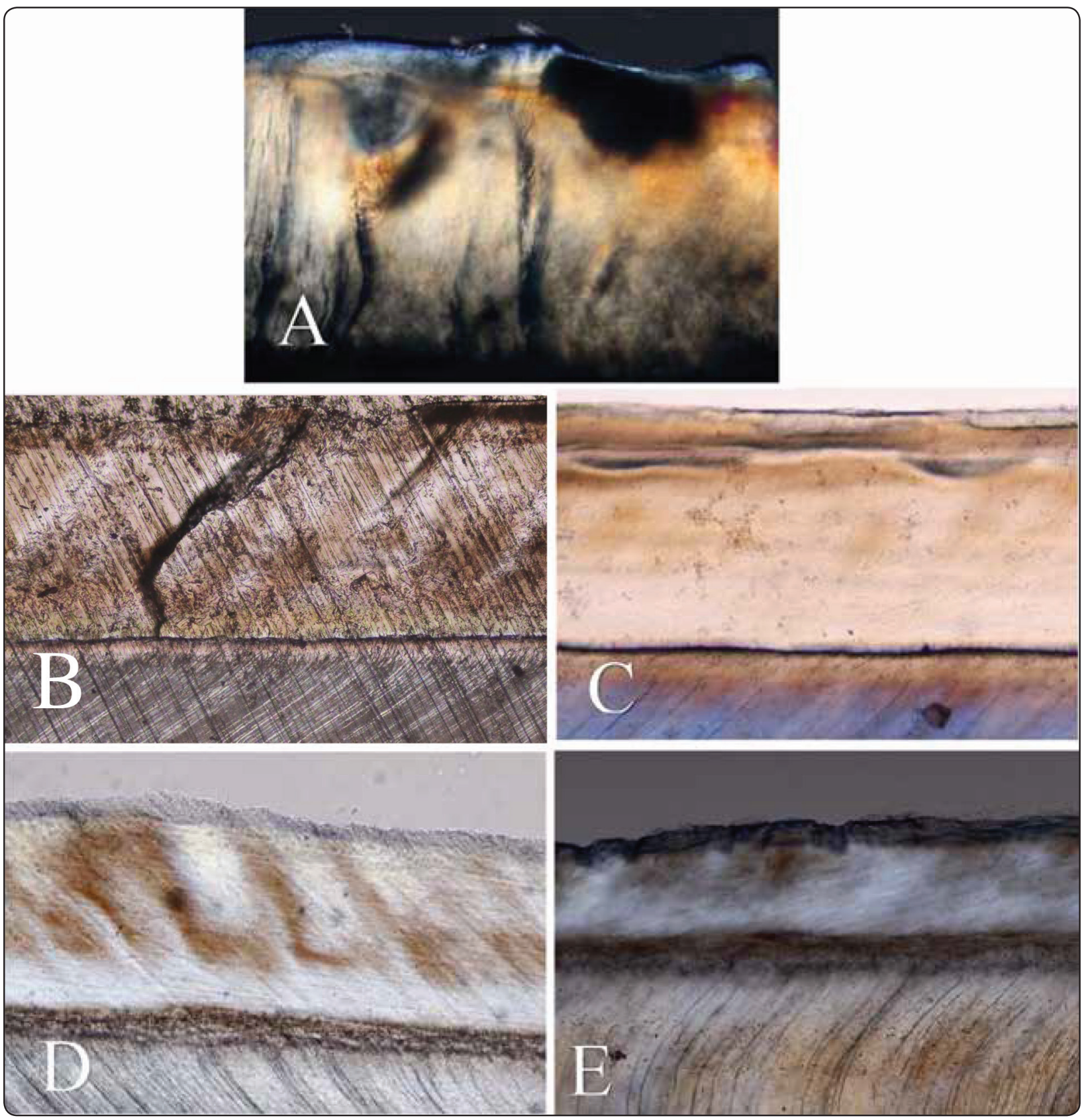

Fig. (1): Polarized light micrograph of longitudinal ground section (x10) showing (a) artificially demineralized enamel lesion with well-developed dark body of lesion. (b) homogenous enamel surface. (c) artificially demineralized enamel lesion treated with resin infiltrant. (d) artificially demineralized enamel lesion treated with CPP-ACP. (e) artificially demineralized enamel lesion treated with artificial saliva. 


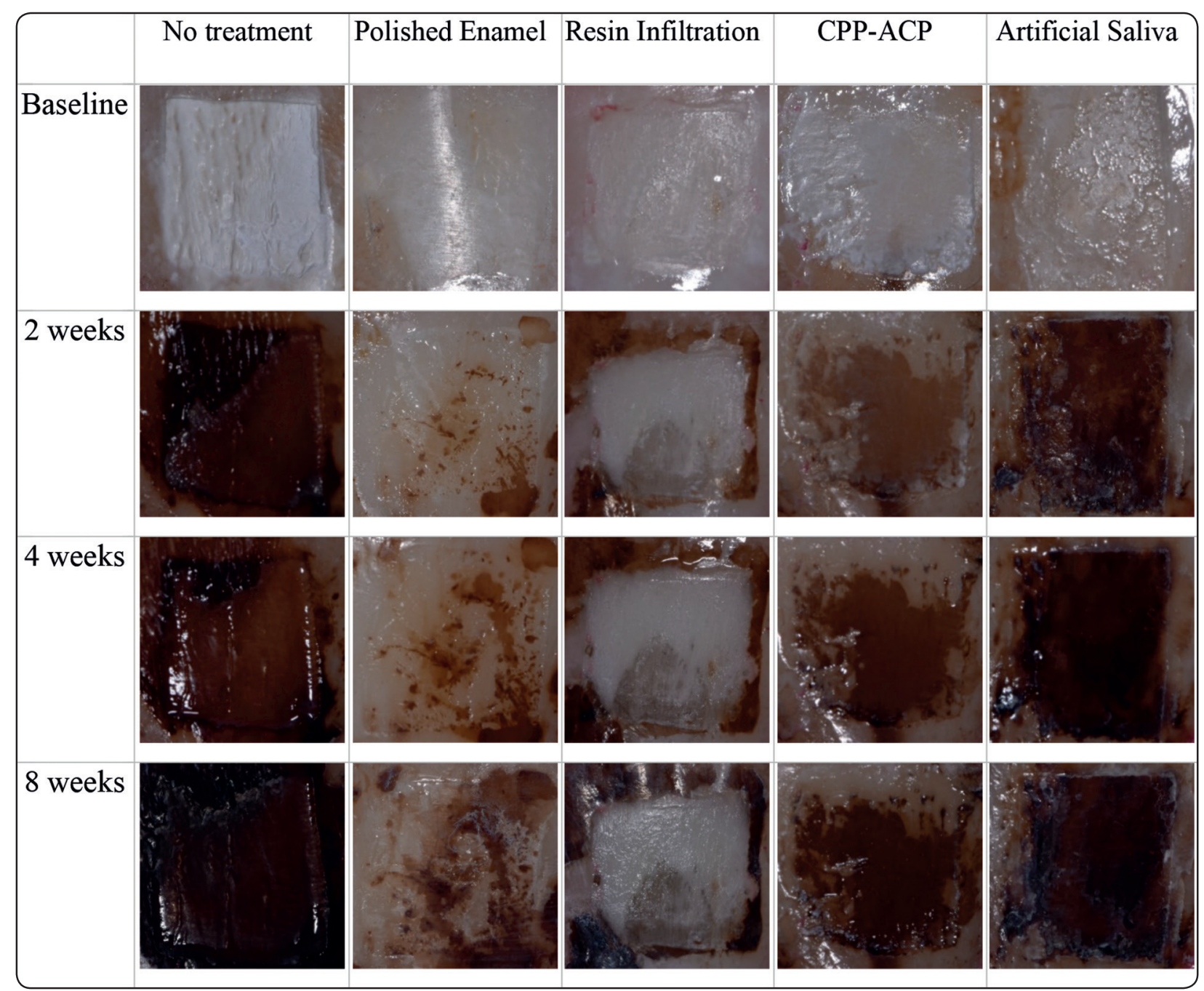

Fig. (2): Clinical photographs showing color change of different surface treatments at different times of immersion.

\section{DISCUSSION}

White spot lesions (WSLs) are early signs of demineralization process resulting in chalky white appearance of the enamel surface. ${ }^{31}$ Several ways have been proposed for treatment of WSLs. However, some socially consumed beverages, such as coffee, Coca-Cola and tea may result in discoloration of the WSLs even after treatment. ${ }^{14}$ Therefore, the aim of the present study was to evaluate the color stability of artificial WSLs treated with resin infiltration compared to CPP-ACP and artificial saliva after immersion in staining solution.
In order to test color stability, a solution exhibiting strong potential for staining both tooth structure and resinous materials was needed. Coffee was preferred for the presence of stronger chromogens as gallic acid compared to tea and cola., ${ }^{3,30}$

Following Ertas et al. (2006) $)^{32}$ and Ardu et al. (2016), ${ }^{25}$ continuous immersion in coffee for a period of 8 weeks was performed to simulate 5 years of daily coffee consumption among coffee drinkers. According to the manufacturer of coffee, the average consumption time for one cup of coffee is 15 minutes and the average consumption 
quantity is 3.2 cups per day. Therefore, a 24-hour storage time was used to reflect one month of coffee consumption. ${ }^{12,32}$

Results of the present study revealed a significant effect of surface treatment on the color stability of WSLs. Color change values for resin infiltration group were the lowest among all the groups. This is further substantiated by the increased depth of penetration of resin infiltration into the body of the lesion as shown in Figure (1,c). This may be attributed to the ability of the low-viscosity resin to completely infiltrate the WSLs by capillarity action thereby blocking the pathways for chromophores as well as acids. ${ }^{26,33}$

Color change values for the resin infiltrant group were the lowest among all the groups. Nevertheless, this group exhibited a perceptible degree of staining, besides increased darkness after 8 weeks of immersion in coffee. In agreement with Borges et al. (2014) ${ }^{3}$, the hydrophilic nature of the TEGDMA-based resin matrix may have increased water sorption, facilitating stain penetration and jeopardizing the color stability of the resin..$^{3,15}$

It can be noted that inadequate polymerization increases resin susceptibility to hydrolytic degradation as a reflection of lower degree of conversion of monomer, resulting in color change. ${ }^{14,34}$ The use of glycerin to prevent oxygen inhibition of polymerization also did not completely eliminate the chances for intrinsic staining. ${ }^{21}$ Furthermore, accessory polishing of the infiltrated surfaces was done to lessen surface roughness and oxygen-inhibited layer. This prevents the resin from getting easily stained by mechanical adsorption and improves the stability of the masking effect. ${ }^{30,35}$

Meanwhile, samples treated with CPP-ACP (GC Tooth Mousse ${ }^{\circledR}$ ) revealed color change values higher than resin infiltration group but still lower than artificial saliva. Unlike resin infiltration, treatment with CPP-ACP resulted in partial penetration to full lesion depth, as shown in Figure (1,d). This may be due to the short application period of only 4 weeks as CPP-ACP is a slow treatment process because of its dependence on the deposition of calcium ions. ${ }^{36}$ Consequently, enamel pores may have been inadequately filled with the remineralizing agent, resulting in incomplete masking of the WSLs. ${ }^{37}$ Therefore, higher color change values and increased darkness upon staining. ${ }^{31}$

Samples immersed in artificial saliva showed color change values higher than both CPP-ACP and resin infiltration. One possible explanation is that artificial saliva resulted only in deposition of minerals on the surface layer leaving the body of the lesion demineralized. ${ }^{3,31,38}$ This incomplete penetration of calcium and phosphate ions into the enamel pores as shown in Figure $(\mathbf{1 , e )}$ allowed the yellow stains present in coffee to permeate the lesions.

According to the results of the present study, time of immersion had a significant effect on the color stability of WSLs. Color change was the highest at 8 weeks. These results are congruent with Lee J et al. (2015) and Nasim et al. (2010) who stated that as the immersion time increase, specimens tend to be darker and color changes become more intense. ${ }^{17,39}$ This can be clarified by the prolonged interaction between the chemical products of the staining solution and the WSL, resulting in significant increase of color intensity rather than its saturation. ${ }^{14}$ For all surface treatments, immersion in coffee has reduced $\Delta \mathrm{L}$ and increased $\Delta \mathrm{E}$ values over time. Moreover, the presence of brown pigments in coffee has directed the $a^{*}$ and $b^{*}$ values towards red and yellow changes, respectively. ${ }^{3}$

Additionally, it should be pointed out that the absence of tooth brushing and dilution of staining solution by saliva may have potentiated the staining susceptibility. ${ }^{3}$ For that purpose and to assure the measuring of only the incorporated internal stains within the WSL, re-polishing of all groups before each color measurement was mandatory in order to remove the superficial stains from the surface layer. ${ }^{12,40}$ 
Therefore, resin infiltration is considered an effective treatment in masking and reducing the staining susceptibility of WSLs after treatment. ${ }^{35,36}$ However, patients should be warned about their potential for staining over time. Furthermore, minimizing the consumption of such chromogenic beverages associated with proper oral hygiene measures should be considered to increase the longevity of these esthetic outcomes. ${ }^{3}$

\section{CONCLUSION}

Under the limitations of this study, it could be concluded that: Resin infiltrant (ICON®) can be considered an effective treatment in masking and reducing long-term staining susceptibility of white spot lesions after treatment.

\section{RECOMMENDATIONS}

CPP-ACP (GC Tooth Mousse ${ }^{\circledR}$ ) seems to need a longer time of application, therefore adequacy of masking of white spot lesions must be verified prior to testing color stability.

\section{REFRENCES}

1. Beerens MW, Van Der Veen MH, Van Beek H, Ten Cate JM. Effects of casein phosphopeptide amorphous calcium fluoride phosphate paste on white spot lesions and dental plaque after orthodontic treatment: A 3-month follow-up. Eur J Oral Sci. 2010;118(6):610-617. doi:10.1111/j.16000722.2010.00780.x

2. Azizi Z. Management of White Spot Lesions Using Resin Infiltration Technique: A Review. Open J Dent Oral Med. 2015;3(1):1-6. doi:10.13189/ojdom.2015.030101

3. Borges A, Caneppele T, Luz M, Pucci C, Torres C. Color Stability of Resin Used for Caries Infiltration After Exposure to Different Staining Solutions. Oper Dent. 2014;39(4):433-440. doi:10.2341/13-150-1

4. Paris S, Meyer-Lueckel H. Masking of labial enamel white spot lesions by resin infiltration--a clinical report. Quintessence Int. 2009;40(9):713-718. http://www.ncbi.nlm.nih. gov/pubmed/19862396.

5. Domejean S, Ducamp R, Léger S, Holmgren C. Resin infiltration of non-cavitated caries lesions: A system- atic review. Med Princ Pract. 2015;24(3):216-221. doi:10.1159/000371709

6. Perdigão J. Resin infiltration of enamel white spot lesions: An ultramorphological analysis. J Esthet Restor Dent. 2020;32(3):317-324. doi:10.1111/jerd.12550

7. Elkassas D, Arafa A. Remineralizing efficacy of different calcium-phosphate and fluoride based delivery vehicles on artificial caries like enamel lesions. J Dent. 2014;42(4):466-474. doi:10.1016/j.jdent.2013.12.017

8. Laila M. El Habashy MH. Effectiveness of casein phospopeptide amormphous calcium phosphate with or without fluoride on reminelization of enamel caries- like lesions in primary teeth. Egypt Dent J. 2020;66:799-808.

9. Munjal D, Garg S, Dhindsa A, Sidhu GK, Sethi HS. Assessment of white spot lesions and in-vivo evaluation of the effect of CPP-ACP on white spot lesions in permanent molars of children. J Clin Diagnostic Res. 2016;10(5):ZC149ZC154. doi:10.7860/JCDR/2016/19458.7896

10. Bakry AS, Abbassy MA. Increasing the efficiency of CPP-ACP to remineralize enamel white spot lesions. J Dent. 2018;76(November 2017):52-57. doi:10.1016/j. jdent.2018.06.006

11. Omar Abd El Sadek ElMeligy, Shimaa Tag Eldin Ibrahim NMA. Resin Infiltration of Non-Cavitated Proximal Caries Lesions: A Literature Review. J Oral Hyg Heal. 2018;06(01):1-8. doi:10.4172/2332-0702.1000235

12. Ceci M, Rattalino D, Viola M, et al. Resin infiltrant for non-cavitated caries lesions: Evaluation of color stability. J Clin Exp Dent. 2017;9(2):e231-e237. doi:10.4317/ jced.53110

13. Zhao X, Ren YF. Surface properties and color stability of resin-infiltrated enamel lesions. Oper Dent. 2016;41(6):617-626. doi:10.2341/15-319-L

14. Cohen-Carneiro F, Pascareli AM, Christino MRC, Vale HF do, Pontes DG. Color stability of carious incipient lesions located in enamel and treated with resin infiltration or remineralization. Int J Paediatr Dent. 2014;24(4):277-285. doi:10.1111/ipd.12071

15. Araújo G, Naufel F, Alonso R, Lima D, Puppin-Rontani R. Influence of Staining Solution and Bleaching on Color Stability of Resin Used for Caries Infiltration. Oper Dent. 2015;40(6):E250-E256. doi:10.2341/14-290-1

16. de Marsillac M de WS, Delbem ACB, Vieira R de S. Effect of time in hardness test on artificially demineralized human dental enamel. Brazilian J Oral Sci. 2008;7(24):15071511. doi:10.20396/bjos.v7i24.8643022 
17. Lee J, Chen J-W, Omar S, Kwon S, Meharry M. Evaluation of Stain Penetration by Beverages in Demineralized Enamel Treated With Resin Infiltration. Oper Dent. 2015;41(1):93-102. doi:10.2341/13-259-1

18. Abbas BA, Marzouk ES, Zaher AR. Treatment of various degrees of white spot lesions using resin infiltration-in vitro study. Prog Orthod. 2018;19(1). doi:10.1186/s40510018-0223-3

19. Shah, Shreyas Pradeepkumar PNB. Polarized light microscopic evaluation of remineralization by casein phosphopeptide-amorphous calcium phosphate paste of artificial caries-like lesion: An. 2016;(252):559-564. doi:10.4103/0972-1363.188761

20. Gmbh CF. Icon ${ }^{\circledR}$.

21. Park H-H, Lee I-B. Effect of glycerin on the surface hardness of composites after curing. J Korean Acad Conserv Dent. 2011;36(6):483. doi:10.5395/jkacd.2011.36.6.483

22. Creme T, Calcium WB, Use DFOR. GC Tooth Mousse ${ }^{\circledR}$ INSTRUCTIONS FOR USE (IFU) GC Tooth Mousse. 2019:4-5.

23. Bailey MW. The Effectiveness of Resin Infiltration and MI Paste CPP-ACP in Masking White Spot Lesions. ProQuest Diss Theses. 2012:53. https://search.proquest.com/docvie w/1151090616? accountid=43793.

24. El-zankalouny SM, Abd WM, Fattah E, Shabrawy SME-. Penetration depth and enamel microhardness of resin infiltrant and traditional techniques for treatment of artificial enamel lesions. 2016;41:20-25.

25. Ardu S, Duc O, Di Bella E, Krejci I. Color stability of recent composite resins. Odontology. 2017;105(1):29-35. doi:10.1007/s 10266-016-0234-9

26. Silva SN, Reich AM, DeLeon E, Schafer T, Rueggeberg FA, Fortson WM. Staining potential differences between an infiltrative resin and an esthetic, flowable composite. J Esthet Restor Dent. 2018;30(5):457-463. doi:10.1111/ jerd.12415

27. JOHNSTON WM, KAO EC. Assessment of Appearance Match by Visual Observation and Clinical Colorimetry. 1989. doi:10.1177/00220345890680051301

28. Bayne SC, Schmalz G. Reprinting the classic article on USPHS evaluation methods for measuring the clinical research performance of restorative materials. 2006;(September). doi:10.1007/s00784-005-0017-0

29. Khashayar G, Bain PA, Salari S, Dozic A, Kleverlaan CJ, Feilzer AJ. Perceptibility and acceptability thresholds for colour differences in dentistry. J Dent. 2014;42(6):637644. doi:10.1016/j.jdent.2013.11.017

30. Padiyar N, Kaurani P. Colour stability : An important physical property of esthetic restorative materials . 2010;1(1):1-4.

31. Tolcachir BR, Crohare L, Gallará RV. Measuring color change of tooth enamel by in vitro remineralization of white spot lesion. J Oral Res. 2015;4(6):371-377. doi:10.17126/joralres.2015.072

32. Erta E, Ler AUGÜ. Color Stability of Resin Composites after Immersion in Different Drinks. 2006:371-376.

33. Arnold WH, Gaengler P. Light- and electronmicroscopic study of infiltration of resin into initial caries lesions-a new methodological approach. J Microsc. 2012;245(1):26-33. doi:10.1111/j.1365-2818.2011.03540.x

34. Al-Abdullah AS, Al-Bounni RS, Al-Omari M. Color Stability of Tetric ${ }^{\circledR}$ N-Ceram Bulk Fill Restorative Composite Resin after Immersion in Different Drinks. J Acad Adv Dent Res. 2017:222941121772908. doi: $10.1177 / 2229411217729080$

35. Paris S, Schwendicke F, Keltsch J, Dörfer C, Meyer-Lueckel H. Masking of white spot lesions by resin infiltration in vitro. J Dent. 2013;41(SUPPL.5). doi:10.1016/j. jdent.2013.04.003

36. Yuan H, Li J, Chen L, Cheng L, Cannon RD, Mei L. Esthetic comparison of white-spot lesion treatment modalities using spectrometry and fluorescence. Angle Orthod. 2014;84(2):343-349. doi:10.2319/032113-232.1

37. Torres CRG, Borges AB, Torres LMS, Gomes IS, De Oliveira RS. Effect of caries infiltration technique and fluoride therapy on the colour masking of white spot lesions. J Dent. 2011; 39(3):202-207. doi:10.1016/j.jdent.2010.12.004

38. Monteiro D, Moreira A, Cornacchia T, Magalhães C. Evaluation of the effect of different enamel surface treatments and waiting times on the staining prevention after bleaching. J Clin Exp Dent. 2017;9(5):e677-e681. doi:10.4317/ jced.53712

39. Nasim I, Neelakantan P, Sujeer R, Subbarao C V. Color stability of microfilled, microhybrid and nanocomposite resins - An in vitro study. J Dent. 2010;38(1500):e137e142. doi:10.1016/j.jdent.2010.05.020

40. Türkün LŞ, Türkün M. Effect of bleaching and repolishing procedures on coffee and tea stain removal from three anterior composite veneering materials. J Esthet Restor Dent. 2004;16(5):290-301. doi:10.1111/j.1708-8240.2004. tb00056.x 